New Zealand journal of industrial relations, 1983 8, 197-203

\title{
The private sector bargaining process and registered collective agreements.
}

\author{
Pat Walsh*
}

\section{Introduction}

Over the last 2 decades, New Zealand's private sector industrial relations system has fragmented into a system in which bargaining takes place at a number of levels with markedly differing procedures and criteria which lead to several different kinds of agreements. It is important that a satisfactory classification scheme be established for the variety of agreements now negotiated, since each category signifies something very different about the nature of the bargaining between unions and employers. If we leave to one side the vitally important area of unregistered agreements (which pose a different set of research problems), there is a general consensus that the classification system used for registered agreements is unsatisfactory.

The most recent effort to construct an alternative classification system is that of A.J. Geare in an article in this journal : "Formal collective agreements in New Zealand privatesector industrial relations" (April 1983). This brief comment on Geare's article is divided into 2 parts : it is argued firstly, that Geare's analysis of settlement data is unacceptable and cannot be used to support the conclusions he draws; and secondly, that analysis based upon his classification system misrepresents the nature of the bargaining process.

\section{Aggregate settlement data}

Before turning to Geare's classification system, some initial comments on his analysis of aggregate settlement data are called for. In his first table (p.25) Geare presents the aggregate number of arbitrated, conciliated and voluntary settlements for the years 1975 . 1981. He observes that "Table 1 shows that, for 1979-1981, collective agreements (voluntary) form a much higher proportion of total collective agreements than they did in 1975 . 1977 " (p.24). In view of this statement, it is rather surprising that Geare gives only aggregate numbers without giving the proportions. Once the proportions are calculated by the reader, it is found that in the $1975-1977$ period, 51 percent of total settlements were voluntary (excluding the 5 composite agreements in 1975), while for the 1979-1981 period 59 percent were voluntary.

It is not clear why Geare concludes that the 59 percent figure for the $1979-1981$ period constitutes a "much higher proportion" than the 51 percent figure for the period 1975 . 1977. To justify this conclusion Geare would need to offer a theory of the bargaining system that explained why a shift in the proportion of voluntary settlements from 51 percent to 59 percent should be considered significant. In the absence of such a theory, the claim that 59 percent constitutes a "much higher proportion" than 51 percent remains purely a matter for debate, and a fruitless debate at that.

A more fundamental problem is that Geare offers no explanations as to why the data

* Lecturer, Industrial Relations Centre, Victoria University of Wellington. The author wishes to thank Paul Stapp, Ralph Stockdill, and 2 anonymous referees for their helpful comments. 
were grouped and analysed in this eay. Consequently, the groupings appear to be entirely arbitrary rather than being informed by any theoretical considerations. It appears that Geare wishes to show that the gross figures indicate an apparent increase in the proportion of voluntary settlements, but he offers no theoretical justification for his methodology. For example, there is no explanation given as to why 1978 is excluded from the analysis. The -exclusion of 1978 alters the conclusions. Once 1978 is restored to the data set and added to the earlier period, then the observed increase in the proportion of voluntary settlements declines noticeably, with 54 percent of settlements in the 1975-1978 period being voluntary compared with 59 percent for 1979-1981. Its inclusion with the latter period makes only a negligible difference to the proportions. The real point is that if Geare wishes to group the data he should do it properly, and not arbitrarily exclude one year altogether.

However since Geare offers no theoretical justification for grouping the data, and since bargaining occurs on an annual basis, it would seem more sensible to analyse each year separately in order to evaluate annual fluctuations. This is done in Table 1 which shows that the annual proportion of voluntary settlements has see-sawed quite markedly between 1975 and 1981 , and that the proportion for 1981 is precisely the same as in $1976 .^{1}$

Table 1 Voluntary settlements as a proportion of total settlements : 1975-1981

\begin{tabular}{ccc}
\hline Year ending 31 March & Total settlements & Proportion voluntary (percent) \\
\hline 1975 & 408 & 44 \\
1976 & 668 & 57 \\
1977 & 500 & 49 \\
1978 & 722 & 60 \\
1979 & 727 & 57 \\
1980 & 756 & 64 \\
1981 & 924 & 57 \\
\hline
\end{tabular}

Source: Geare (1983) Table 1.

Fluctuations such as these are completely obscured by an analysis based upon grouped data. By ignoring annual variations, misleading conclusions can be drawn about nonexistent trends. As Shalev observes in a comment upon Hibbs' (1978) analysis of strike trends since 1900, ". . . in all countries the occurrence of extreme fluctuations, however occasional, makes the use of periodized data a hazardous venture" (Shalev, 1978, p.438). These hazards loom even larger in analyzing a 7 year period that exhibits such striking annual fluctuations. Thus, Geare's conclusion that there has been an apparently significant increase in the proportion of voluntary settlements is not supported by a more appropriate method of analysis.

1 Quite clearly, something is causing these annual fluctuations. A full analysis of this is outside the scope of this article. However, it is possible to suggest some tentative hypotheses. Unions and employers may register an initial voluntary collective agreement (VCA) in order to establish a house relativity with the award or another VCA, and subsequently maintain that relativity by means of unregistered agreements. This would generate annual fluctuations in the number of registered VCAs. Secondly, during the 1970 s a number of VCAs were for a term of 18 months or 2 years, with a wages-reopening (or "common interest") clause after 12 months. The new wage rate (and any other matters renegotiated) would then be registered as a variation on the original VCA, and not as a new VCA. Finally, the Court at times permitted the backdating of agreements, which could thus expire in the same year as they were registered. This meant that it was quite possible for a union and employer to register 2 VCAs in the same year. These latter 2 factors would contribute to the observed 2-yearly cycle in the proportion of registered VCAs. These hypotheses are based on an initial examination of registered agreements, and I hope to confirm or reject them in subsequent research. 


\section{Geare's classification system}

Geare's alternative classification system and its application to 1980 is shown in Table 2. Clearly there is, as Geare points out, a need to distinguish between arbitrated and conciliated awards, and the failure of the present classification system to do this is inexcusable. This paper is concerned with Geare's distinction between principal and supplementary agreements, and his analysis based on that.

Table 2 Collective arrangements under the Industrial Relations Act 1973 reached in 1980

\begin{tabular}{lr}
\hline Collective arrangement & Number \\
\hline Involving registered unions & 7 \\
Awards : arbitrated (principal) & 263 \\
Awards : conciliated (principal) & 315 \\
Collective agreements (principal) & 196 \\
Collective agreements (supplementary) & 27 \\
Composite agreements (principal) & 10 \\
Composite agreements (supplementary) & 31 \\
Involving unregistered societies & 2 \\
$\quad$ Voluntary agreements (principal) & \\
Voluntary agreements (supplementary) & \\
\hline
\end{tabular}

Source: Geare (1983) Table 2.

Geare argues (p.24) that voluntary settlements should be classified into principal and supplementary documents, and that when this is done, the trend towards voluntary settlements which he has observed (but which the analysis above casts doubt upon) is shown in a new light. Geare defines a principal document as one "which stands by itself with regard to questions governing the work environment" (p.24). A supplementary document "is one which is the authority for only a small proportion of rules and must be read in conjunction with a principal document" (p.24). He argues that if a large proportion of voluntary agreements are supplementary documents, then we cannot conclude that there is a trend away from conciliation towards independence for negotiators and the development of genuine voluntary negotiations.

Geare then classifies agreements in 1980 into principal and supplementary documents, and concludes that "in 1980, at any rate, a large proportion of collective agreements were supplementary" (p.24). In fact, as Geare's own data (reproduced in Table 2) show, 38 percent of VCAs in 1980 were supplmentary agreements, while the great majority - 62 percent - were principal. In addition, only 27 percent of composite agreements and 6 percent of voluntary agreements were supplementary documents. It is possible that these represent large figures for supplementary agreements, but we can only judge this by comparison with other years. Data based upon one year tell us nothing about longer-term trends. Geare gives no reason for his exclusive focus on 1980 . He does not suggest that 1980 is typical of all other years, and there is certainly no $a$ priori reason to suspect that it is. Certainly Geare's implied reservation about the reliance on 1980 ( . . " "in 1980, at any rate ....") suggests an awareness on his part of its methodological and theoretical fragility. Nor will it do to argue that the 1980 figures are suggestive or heuristic. They are suggestive of what happened in 1980 and no more than that.

\section{Geare's analysis}

It should be noted that the principal/supplementary document distinction itself may offer a fruitful basis for analysis, and indeed Law (1981) has used a similar classification 
system to analyse the distribution of particular provisions across national, principal and supplementary documents. The major objection here is to the analysis which Geare makes, based upon his classification system.

However, it is important to be precise about the status of VCAs, whether principal or supplementary, and the relationship between the two kinds of VCAs. Geare observes (p.24) that a supplementary agreement must be read in conjuction with a principal agreement for those matters not included in the supplementary agreement. This is quite true, but, it should be pointed out that a supplementary VCA cannot be read in conjunction with a principal VCA, but only with an award. A VCA cannot refer back to (or "superimpose on") another VCA. It should also be noted that a VCA, by virtue of section 65 (8) of the Industrial Relations Act, supersedes any award that might otherwise apply. This means that it is possible for a VCA to set terms which are inferior to those in the award. Examples of this are rare but not unknown. ${ }^{2}$

As noted above, Geare concludes that the proliferation of supplementary agreements that settle only a small number of issues cannot support any conclusion about a shift towards genuine voluntary negotiations and the independence of negotiators. This involves an assumption that all issues in an agreement are of equal significance in its negotiation, and that we can learn something from counting the number of issues settled in an agreement. But all issues are not born equal. Many are settled before any negotiation takes place and typically "negotiation" involves their ritualistic insertion into the agreement. Some are prescribed by statute - hours of work, the term of the agreement, public holidays, annual holidays, certain safety standards, right of entry for union officials, disputes of right procedures, and personal grievance procedures, ${ }^{3}$ while others are prescribed by custom and practice that leave very little flexibility for negotiators - the unqualified preference clause, payment of wages, smokos, meal breaks, overtime rates etc. In practice, the number of issues that are actually negotiated may be quite small. Of those that are negotiated, the crucial issues are usually those concerning basic wage rates and allowances, and in the negotiation of most awards and agreements these are heavily influenced by the pattern set in the trendsetting awards (Bradford, 1983).

Thus we learn nothing of any significance about the autonomy of negotiators from counting the number of issues settled in an agreement. The autonomy of negotiators can only be assessed by evaluating the substance of the issues settled. Where negotiators of any agreement - be it "principal" or "supplementary" - negotiate terms that depart from the prevailing trend, then we may speak of their autonomy, regardless of the number of clauses in the agreement. This is particularly so where the negotiators depart from prevailing trends in settling the crucial issues of wages and allowances, or other issues that may

2 Compare the provisions for wages and allowances in the Invercargill City, Gore Borough, Bluff Borough, Gardeners, Labourers and Other Workers VCAs in 1979 and 1980 (Book of Awards, 79, 7271 ; and 80, 7117) with the New Zealand (with exceptions) Local Bodies Gardeners, Labourers and General Workers Awards of those years (Book of Awards, 79, 5775; and 80, 1569). Although the terms of the documents are not precisely the same, in each year the VCA was registered after the award and contained rates inferior to the award. The net effect was that for several months in each year, the workers covered by the VCA were paid at below-award rates. It is possible that as employer opposition to the award system grows, employers may come to view this as an effective strategy to impose below-award conditions.

3 Of course these issues are not entirely removed from the realm of bargaining. For example, where the normal working week goes beyond the prescribed 40 hours, the parties will need to negotiate the appropriate terms of employment. Alternatively, some unions may seek to improve upon the terms prescribed by the legislation, such as by obtaining an extra week's holiday after a specified period of service with the long-term aim of eventually securing a change to the legislation. In the area of disputes and grievance procedures, the legislation makes alternative grievance and disputes procedures possible, but Miller's analysis suggests that the vast majority of agreements follow the procedure in the legislation $(1983, \mathrm{p} .8)$. Thus the bargaining situation is always fluid, and particular agreements may depart marginally or, more rarely, significantly from the terms prescribed by statute. However, at a general level, direct challenges to statutorily prescribed terms of employment are not a prominent feature of the system. (For instance even the celebrated "evasions" in the 1970 s of statutorily prescribed wage levels were usually conducted by means of the legally permitted safety valves of "serious anomalies" or "exceptional circumstances".) 
be significant at a particular time, such as redundancy payments in the mid-1970s.

Consequently, if supplementary agreements involve terms of employment that depart from prevailing trends, especially on significant issues, then they are very important documents indeed, and their proliferation would indicate precisely that growing independence of negotiators that Geare argues against. Since Geare's counting method tells us nothing about the substance of the rules in most supplementary documents, we cannot be certain whether this is the case or not. However, Geare does observe that a large number of supplementary documents in 1980 were negotiated by the Engine-Drivers Union, and involved "improved service and shift allowances, meal money and extra monies for particular working conditions" (p.26). These agreements also settled the basic wage rate for the workers covered by them. This suggests that these supplementary documents concerned precisely those issues that are the essence of negotiations.

This conclusion is further supported when we consider that the 1980 Engine-Drivers' agreements were the continuation of a campaign begun by the union in 1979 to secure both these payments and the registration allowance for boiler-attendants through voluntary agreements. In announcing the house agreement campaign, the vice-president of the union stated that the award had become almost irrelevant to the union as it covered only 25 percent of the membership, and set a basic rate of $\$ 3.20$ per hour compared with an Auckland freezing industry ruling rate of $\$ 4.71$ per hour (Evening Post, 10 January 1979). If anything then, it is the award which is the "supplementary" agreement in this case, with house agreements settling the most important issues, including the basic wage rate, and the award settling those other issues for which the scope of negotiation is severely constrained by legislation or custom. The union embarked upon this strategy when the Government threatened to issue regulations preventing the negotiation of these payments in the award. The campaign gathered further momentum in 1980 when the Government did issue regulations under the Remuneration Act to determine the terms of the award. It seems reasonable to conclude that the successful campaign by the Engine-Drivers Union to negotiate certain payments through voluntary agreements ("supplementary documents") in the face of threatened and then actual government regulation constitutes a remarkable degree of independence on the part of the negotiators, and a significant shift away from conciliation and towards genuine voluntary negotiations.

It is also important to point out that Geare's supplementary agreement category contains a heterogenous group of documents. As he points out (p.27), another large group of these agreements that were negotiated in 1980 included those negotiated by the Canterbury Clerical Workers Union, in which the only variation from the national award was the provision for the automatic deduction of union subscriptions from workers' wages. These documents involved procedural matters, and were very different from those negotiated by the Engine-Drivers Union which established major variations from the award on substantive matters. If the principal/supplementary agreement distinction is to be useful, it needs to distinguish between procedural and substantive agreements. Clearly the reasons for the negotiation of the Clerical Workers' agreements were quite different from those that led the Engine-Drivers into their agreements, and each signifies something different about the industrial relations system. A classification system which classifies them as one homogenous category ignores this, and misrepresents the bargaining process.

The Engine-Drivers' house agreement campaign further illustrates Geare's failure to take full account of the reasons why one kind of agreement is negotiated rather than another. Geare analyses this simply in terms of a 2-party relationship in which union and employer preference for a particular kind of agreement can be understood in terms of their strategic evaluation of such variables as the blanket clause, the concentration of union membership, the degree of membership cohesion and loyalty, and employer differences in profitability, amenability to voluntary agreements and mode of operation (p.27-7). But the predominant characteristic of the bargaining system in the period under consideration was that it was a 3-party relationship involving almost continuous State intervention, or threatened intervention. The bargaining choices that unions and employers make, and the corresponding changes in the types of settlements reached must be analysed in terms of this historical 
context. ${ }^{4}$

These problems are illustrated more vividly in Geare's discussion of composite agreements, where he argues that the choice to adopt or not adopt the composite agreement option is determined by the simplicity of the procedure for its negotiation. He states that:

The purpose of the composite agreement is to substitute one agreement for many, on a major project or in a major concern. The concept was introduced in 1962 but did not prove popular as the procedure then specified was complex [in contrast to the simplified procedure introduced in the 1973 legislation] (p. 27).

A number of objections can be made to this. First, the "concept" of a composite agreement was not "introduced" in 1962. The legislation setting out a procedure for their negotiation was enacted in 1962, but the concept was "introduced" at least a decade earlier with the negotiation of a comprehensive agreement at the Roxburgh hydro-electric site in 1952 and the negotiation of comprehensive (composite) agreements at other major sites such as Mere-Mere, Kawerau, and Marsden Point in subsequent years. ${ }^{5}$

Secondly, Geare's account of the "purpose" of a composite agreement is simply a formal statement of what a composite agreement is and actually says nothing at all about its purpose. The composite agreement constitutes a rationalisation of the bargaining structure on major sites for the purpose of overcoming the problems posed for management by multiple agreements. These problems involved firstly the inappropriateness of awards or agreements negotiated outside the site for the settlement of issues which arose out of the very different employment conditions on site. Secondly, the existence of multiple agreements with the numerous unions on site, posed management with constant pressure from the different unions to grant terms more favourable than those enjoyed by other unions. This pressure led to a ratcheting upwards of wages, allowances and conditions on site and to a disturbance of existing relativities which had implications for sub-contractors on site and for employers outside. Thus the provision for composite agreements in the $1962 \mathrm{Act}$ was an employer-initiated proposal which unions strongly opposed from when it was first suggested in the mid-1950s until it was finally enacted in 1962. Its purpose was to overcome the problems for employers posed by a fragmented bargaining structure, which, in turn, was a consequence of the fragmented union structure imposed by industrial legislation.

Geare's argument that composite agreements did not prove popular in the 1960 s because the procedure was complex is equally misleading. In fact, composite agreements were initially unpopular with unions after the 1962 legislation because they were viewed as a government/employer strategy to eliminate a bargaining leverage for unions, and because they were seen as a threat to union autonomy. This latter factor was particularly important in the negotiation of composite agreements after 1962. The unions had agreed to the comprehensive agreements of the 1950 s on sites such as Roxburgh where the vast majority of workers were covered by the New Zealand Workers Union, and on other sites where they were settled in direct bargaining outside the arbitration system. But on sites where many unions had a significant presence, efforts to impose a composite agreement within the arbitration system triggered union resistance against a dictated bargaining procedure, sparked intense inter-union conflict over jurisdictional matters, and led to bitter accusations that the agreement negotiated was less favourable than an individual union had already negotiated elsewhere, or would have negotiated on the project if left to negotiate alone. Indeed, the negotiation of the Manapouri composite agreement in 1963 involved fierce union clashes at Arbitration Court hearings, appeals to higher courts, a decision by the Workers Union to withdraw from the FOL (subsequently reversed) and frequent

4 This is not to suggest that the nature of the bargaining system was exclusively determined by State intervention, but rather that this intervention was the predominant characteristic of the bargaining system in that period, and that any analysis which excludes consideration of it does so at great peril.

5 See Federation of Labour Bulletin 2 (8), 1963 for a summary of this. 
inter-union conferences to settle the intense conflicts that had been generated. ${ }^{6}$

Unions attitudes slowly changed as they adjusted themselves to a co-operative bargaining strategy, resolved the jurisdictional conflicts, and began to realize that the capital-intensive nature of major projects permitted the negotiation of very favourable terms of employment. These could be used to put pressure on other employers, through the house bargaining strategy discussed above. These changes, combined with the rather obvious fact that there were more major projects and large manufacturing concerns in the 1970s than in the 1960 s, help explain the greater number of composite agreements in the 1970s as much, if not more than Geare's emphasis on the simplified procedures set out in the 1973 legislation.

However, the problems associated with composite agreements have not been entirely overcome as Albury (1983), writing in the same symposium as Geare, illustrates with his analysis of the maritime composite agreement. Indeed Albury's analysis, which is firmly grounded in an explanation of the particular union/employer/government relations in the maritime industry, contributes more to an understanding of industrial relations than does Geare's formal and ahistorical sweep across the board canvas.

\section{Conclusion}

The construction of categories exercises a strong influence upon subsequent research, and directs attention to certain questions and areas rather than others. We perceive and understand the world by means of the categories we look through, and if they are developed in isolation from the real world, subsequent research based upon them will be similarly isolated. Thus Geare's classification system would categorise the Engine-Drivers' award as a principal document that "stands alone". But it only stands alone because the important matters are settled elsewhere. Secondly, fully half of his article comes under the heading "The choice of agreements", where he quite properly attempts to explain why different kinds of agreements are chosen rather than others. Without this, his classification system would "stand alone" as an atheoretical exercise divorced from the explanation of the real world of industrial relations. Unfortunately, his analysis of the process of choice is inadequate.

\section{References}

Albury, P.F. (1983) The 1975-1979 maritime composite agreement New Zealand journal of industrial relations $8(1): 39-46$.

Bradford, M. (1983) Issues of concern to employers. In R.J. Harbridge (Ed) Industrial relations: issues of concern Wellington Industrial Relations Centre, Victoria University of Wellington.

Hibbs, D. (1978) On the political economy of long-run trends in strike activity British journal of political science $8(2)$ : 153-77.

Law, M. (1981) Family leave and union business provision in New Zealand industrial documents Centre for Continuing Education, University of Waikato.

Miller, R.L. (1983) The resolution of disputes and grievances in New Zealand Wellington Industrial Relations Centre, Victoria University of Wellington.

Roth, H. (1973) Trade unions in New Zealand Wellington, Reed.

Shalev, M. (1978) Strikes and the state: a comment British journal of political science 8(4): 479-497.

6 These events are not well documented in the secondary literature. However accounts of them are available in trade union journals of the period (for example, see FOL Bulletin, September 1963 and Waterfront, September 1963) and newspaper reports between September and December 1963. For the relevant Arbitration Court hearings, see Book of Awards 1963. 